\begin{tabular}{|l|l|}
\hline Postprint Version & 1.0 \\
\hline Journal website & http://dx.doi.org/10.1016/j.srhc.2010.08.004 \\
\hline Pubmed link & $\underline{\text { http://www.ncbi.nlm.nih.gov/pubmed/21122620 }}$ \\
\hline DOI & $10.1016 /$ j.srhc.2010.08.004 \\
\hline
\end{tabular}

This is a NIVEL certified Post Print, more info at http://www.nivel.eu

\title{
Maternity care and birth preparedness in rural Kyrgyzstan and Tajikistan
}

\author{
T.A. WIEGERS ${ }^{A} *$, W.G.W. BOERMA ${ }^{A}$, O. DE HAAN ${ }^{\mathrm{B}}$
}

a NIVEL, P.O. Box 1568, 1500 BN Utrecht, The Netherlands

b NSPOH, P.O. Box 2557, 1000 CN Amsterdam, The Netherlands

\begin{abstract}
A B S T R A C T Objective: To assess a baseline level of maternity care knowledge of the population and of care providers in rural areas in Kyrgyzstan and Tajikistan (Central Asia). Methods: Interviews with pregnant women and with men about their knowledge of key danger signs, serious health problems during pregnancy, labour and childbirth, and knowledge of basic infant care. Questionnaires about maternity care knowledge for providers, and checklists about providers' communication and counselling skills and about facilities completed by observers. Results: Level of knowledge among the population about possible complications during pregnancy and the postpartum period was low. Physicians in Kyrgyzstan scored an average of 55.2\% correct answers on 52 knowledge questions about maternity care. Midwives and nurses in Kyrgyzstan, physicians and midwives in Tajikistan, scored on average less than $50 \%$ correct answers. In Kyrgyzstan, in seven out of 15 facilities (47\%) staff was permanently available for treatment and referral of patients (24 h a day, 7 days a week). In Tajikistan this was the case in only 2 of 17 facilities (12\%). Conclusion: Kyrgyz and Tajik women and men have limited knowledge about possible complications during pregnancy, childbirth, and the period after childbirth. Service providers do not have an adequate professional level of knowledge of perinatal health issues and lack basic skills to monitor their work.
\end{abstract}

\section{INTRODUCTION}

Since the disintegration of the Soviet Union the economic and healthcare situation in the newly independent Central Asian countries has deteriorated. Kyrgyzstan and Tajikistan are among the poorest countries in the WHO European region, with a broken down healthcare system and very poor health outcomes. To improve health outcomes not only a properly functioning healthcare system is needed, but the population also need to be able to use it. Maternity care is an area where relatively small improvements can have large and long lasting effects on the health of the population. In 2006 the Netherlands School of Public and Occupational Health (NSPOH) launched a Safe Motherhood project, called: 'Services to the People', in collaboration with family planning associations in Kyrgyzstan and Tajikistan. The aim of this project was to bring the necessary services to women who cannot themselves go to the healthcare services. The project is funded by the Dutch Ministry of Foreign Affairs and runs from January 2006 to January 2011 [1]. It started with a baseline study to assess the knowledge and perception of maternity care in the population as well as among care providers in rural areas in both countries, before starting an educational program to improve maternity care outcomes. The educational program consisted of the WHO-training in effective perinatal care and a training in effective patient-doctor communication for maternity care providers and 'Parent Schools' for pregnant women and their partners (husband, mother-in-law, or anybody with whom the woman has a trusting relationship). In this paper the results of the baseline study are presented. 
Wiegers, T.A., Boerma, W.G.W., Haan, O. de. Maternity care and birth preparedness in rural Kyrgyzstan and Tajikistan. Sexual \& Reproductive Healthcare: 2010, 1(4), 189-194

\section{The countries in this study}

The Kyrgyz Republic (or: Kyrgyzstan) and the Republic of Tajikistan, both former Soviet republics, are neighbouring states in Central Asia, situated at the Chinese border, north of Afghanistan and south of Kazakhstan. Kyrgyzstan is a medium size country, somewhat smaller than Belarus and Romania, with a relatively small population of 5.2 million people. Tajikistan is smaller than Kyrgyzstan but has a larger population (6.5 million), which is heavily concentrated in the western regions [2]. Both countries are very mountainous with $30 \%$ of the Kyrgyz territory and half of the Tajik territory above $3000 \mathrm{~m}$. About two thirds of the populations in both countries are living in rural areas. Measured by their Gross Domestic Product (GDP) per capita, Kyrgyzstan and Tajikistan belong to the poorest four among the 53 countries that make the WHO European Region with US \$1972 and US \$1356 PPP (purchasing power parity), respectively, in the year 2005. As a comparison: in the UK and the Netherlands the GDP (PPP) per capita was US \$33,238 and US \$32,684, respectively, in that year. Health outcomes are similarly poor. Life expectancies of men and women are 59 and 67 years, respectively, in Kyrgyzstan and 62 and 64 years in Tajikistan. In comparison: life expectancy in the UK and the Netherlands is about 78 for men and 82 for women [3]. Before 1991 both states had a Soviet-style healthcare system with a high level of public services, including free healthcare for all citizens. However, with the disintegration of the Soviet Union the system with its universal free-of-charge healthcare provision has fragmented. Furthermore, ethnic and civil unrest led to a prolonged and profound economic recession that has negatively impacted the healthcare systems in these countries [4-8]. Tajikistan still holds onto a centrally planned structure, based on the Soviet model of healthcare, with the state as the main public funder and provider of healthcare services [9]. In Kyrgyzstan donor-supported health reform has led to a mandatory health insurance, increased autonomy of local health facilities, emergence of a private health sector (mainly located in large cities), and development of a system of primary care facilities, family medicine centres and a public health service [10]. As Falkingham [11] and Veenema [8] describe, a significant decline in the use of maternal healthcare services occurred in both countries since they gained independence from the Soviet Union in 1991, including in Tajikistan a clear shift away from giving birth in a medical facility to giving birth at home $[8,11]$. Because poor pregnancy outcomes, such as neonatal and maternal mortality, are related to poor healthcare, improving healthcare provision and healthcare utilisation have become important issues. In both countries the level of care during pregnancy and childbirth is low and maternity care statistics are disconcerting. For instance: WHO-estimates for neonatal mortality rates were 31 per 1000 in Kyrgyzstan and 38 in Tajikistan in the year 2000 (latest available data) [12]. As a comparison: in the UK and the Netherlands the neonatal mortality rate was 4 per 1000 and in France and Germany 3 per 1000 that year [12]. The maternal mortality rate (number of maternal deaths per 100,000 live births) in Kyrgyzstan and Tajikistan in 2000 was 110 and 100, respectively (official data), while in Western Europe it was 17 (France), 16 (the Netherlands), 11 (UK) or 9 (Germany) [13]. Moreover, in Tajikistan 29\% of women gave birth without the assistance of a skilled birth attendant in 2000 and 25\% of pregnant women received no antenatal care from a skilled birth attendant at all. In Kyrgyzstan these figures were less dramatic but still $12 \%$ of pregnant Kyrgyz women received no antenatal care from a skilled professional in 1997 (latest available data) [12].

\section{Maternity care}

In Tajikistan maternity care is organized at the local level with mainly public health services (health posts for vaccination and basic antenatal services, no highly skilled care providers). At the regional level there are general, mainly low risk maternity care services (rural health centres (RHC), medical facilities with a few beds, staffed with three medical practitioners). At district level the same type of services as at the regional level are available, but for a larger population (rural district hospitals, similar to RHC's but with 10 or more beds). The highest level consists of a central district hospital with in- and outpatient facilities and specialist staff [9]. Informal care may be provided by traditional birth assistants (TBAs). In Kyrgyzstan the first point of contact for a pregnant woman is the local health centre, staffed by nurses and sometimes midwives and, in larger villages and towns, by retrained general practitioners, for basic antenatal and postnatal care. In cities maternity care is provided in outpatient clinics, freestanding or integrated in a hospital, staffed by primary care physicians and medical specialists. Inpatient care is provided by district hospitals and regional hospitals. Deliveries usually take place in the maternity departments of district hospitals [14]. 
Wiegers, T.A., Boerma, W.G.W., Haan, O. de. Maternity care and birth preparedness in rural Kyrgyzstan and Tajikistan. Sexual \& Reproductive Healthcare: 2010, 1(4), 189-194

\section{Aims of the study}

The first aim was to gain insight into the level of Birth Preparedness and Complication Readiness (BP/CR) of the rural populations of Kyrgyzstan and Tajikistan. The second aim was to gain insight into the level of maternity care knowledge and communication and counselling skills of healthcare providers in the study areas. The results are meant to serve as a baseline upon which to build the Safe Motherhood project 'Services to the People'. Target districts for the project 'Services to the People' in both countries, the regions Chui and Issyk-Kul in Kyrgyzstan and the Chachrinavski district in Tajikistan, were selected on the basis of perceived insufficient level of medical services, especially regarding reproductive health and family planning. The target samples were relatively small: 100 pregnant women and 20 men, and professional staff of approximately 15 health care facilities in each country. A convenience sample, large enough to get a feel of the situation, but not meant to enable elaborate statistical analyses.

\section{STUDY METHODS AND RESPONSE}

To assess the level of BP/CR, a Tool Kit *, developed by the Safe Motherhood Initiative and used in at least 49 developing countries, has been adapted and translated, to be used by local partners of the project in Kyrgyzstan and Tajikistan $[15,16]$. This included a shortened version of the Safe Motherhood Questionnaire for women and for men with, respectively, 32 and 22 questions. Men were included in the research because male participation is a prerequisite for behavioural change, needed to improve the situation. One important aspect of BP/CR is knowledge of key danger signs (signs that should alert a person to seek medical help). Fourteen key danger signs are included in the questionnaires, three during pregnancy, four during labour and childbirth, three during the postpartum period and four for newborns (see Box 1). A score is calculated as the percentage of respondents who know all the relevant key danger signs. In addition, questions were asked about respondents' social-demographic situation, reproductive history, knowledge of serious health problems during pregnancy, labour and childbirth, and knowledge of basic infant care. Women were also asked about their local maternity care facilities. Interviewers were instructed to complete at least 100 interviews with pregnant women and 20 with men from the same households (not necessarily spouses). Households were randomly selected from the list of pregnant women registered at the local medical facility. No registration was made of the number of people that declined participation. Most questions were presented as open-ended questions where the interviewer could tick off any given answer on a precoded list. To assess the level of knowledge and skills of healthcare providers, questionnaires and checklists from the same Tool Kit were used [16]. Providers filled out questionnaires about their knowledge, and observers completed checklists about providers' communication skills and about the healthcare facility. The knowledge questionnaire for maternity care providers consisted of 52 multiple choice questions with for each question one correct answer, regarding antenatal care, normal labour, childbirth, immediate newborn care, management of complications, and postpartum care for mother and baby (see for an example Box 2). Box 2 Example question from the providers' questionnaire. One example of a question concerning antenatal care is: 8 . Focused antenatal care includes which of the following actions? a. ___ Checking the baby's position at 28 weeks b. Checking the woman's blood pressure at every visit c.___ Assessing ankle oedema at 36 weeks $\mathrm{d}$. ___ Counselling the woman about risk signs only at the last visit (The correct answer is b. according to the answer key, included in the Toolkit) N.B.: Focused antenatal care means that providers focus on assessment and actions needed to make decisions, and provide care for each woman's individual situation. See:

http://www.whiteribbonalliance.org/Resources/Documents/ Focused\%20Antenatal\%20Care_Best\%20Practices_JHIPEGO. pdf for more information about focused antenatal care. The providers' communication and counselling skills checklist, filled out by trained observers during a consultation with a client, consisted of 18 items regarding encouraging client participation, responding to client's needs, giving information, and expressing positive emotion. In addition, the observers were asked to conclude the checklist with an indication of competency of the care provider. The facility audit consisted of 85 indicators including facility services (for instance: staff availability), facility infrastructure (for instance: waiting area, examination room, water, light), basic equipment and supplies (for instance: fetoscope, stethoscope, thermometer, syringes, clinical registers, childbirth kit, suture kit, drugs) and additional infrastructure, staff and equipment (for instance: facility to perform laboratory tests, anaesthesia or caesarean section). Facilities were appointed by the Ministry of 
Wiegers, T.A., Boerma, W.G.W., Haan, O. de. Maternity care and birth preparedness in rural Kyrgyzstan and Tajikistan. Sexual \& Reproductive Healthcare: 2010, 1(4), 189-194

Health to participate in the study. The management of the facility decided which care provider would be 7 included. Interviewers and observers were trained by the family planning associations (FPA) in both nivel countries. The FPA received permission from their respective Ministry of Health to conduct this study. The response in Kyrgyzstan was 118 pregnant women, 31 men, 27 providers, 18 completed checklists on communication skills of providers, and 15 completed health care facility audits. The response in Tajikistan was 100 pregnant women, 20 men, 30 providers, 30 completed checklists on communication skills of providers, and 17 completed health care facility audits.

\section{[воX 1]}

\section{[воX 2]}

\section{RESULTS}

Overall, results in both countries point to very little knowledge among women and men about possible complications during pregnancy and the postpartum period. On average the women in Kyrgyzstan gave a much higher rating to their birth facilities than women in Tajikistan, but were at the same time more critical. Knowledge tests among providers in rural areas of Kyrgyzstan and Tajikistan had very poor results. In both countries none of the tested providers passed the criteria on all themes of the test, meaning that none of the providers met the standard for a professional level of medical technical knowledge on pregnancy, delivery and the postpartum period, including infant care.

\section{Knowledge of key danger signs}

None of the Kyrgyz and two of the Tajik women (2\%) spontaneously mentioned all three key danger signs during pregnancy. None of the Kyrgyz or Tajik women mentioned all four key danger signs during labour and childbirth. Only one of the Kyrgyz women $(0.8 \%)$ and two of the Tajik women (2\%) mentioned all three key danger signs during the postpartum period. Of the men in both countries no one spontaneously listed all the key danger signs on any of the categories. None of the respondents, men or women, either in Kyrgyzstan or in Tajikistan, mentioned all four key danger signs for newborns.

\section{Knowledge of serious health problems and basic infant care}

In both countries women mentioned more health problems and were more knowledgeable about basic infant care than men. The kind of problems, as well as the number of problems mentioned, differed between the countries. A few examples are: Tajik women most often mentioned 'bleeding' (72\%) as health problem during pregnancy, while Kyrgyz women mentioned 'sickness/vomiting' (31\%) most frequently. The most often mentioned problem during labour and birth in both countries was 'severe bleeding', but with a striking difference in frequency: by $76 \%$ of Tajik women and by $42 \%$ of Kyrgyz women. 'Severe abdominal pain' was mentioned most often as problem in the days shortly after birth, by $60 \%$ of Tajik women and 30\% of Kyrgyz women. The most frequently mentioned health problems of the newborn baby were: 'often crying' (60\% of Tajik women) and 'discharge from the umbilical cord' (31\% of Kyrgyz women). In Tajikistan 'breastfeeding' was most often mentioned as basic infant care, by $72 \%$ of women, in Kyrgyzstan 'cord care' was most often mentioned (by 51\% of women).

\section{Birth preparedness}

Respondents were asked about their use of antenatal care and their preparations for the coming birth. The results are shown in Table 1. Health care use in Kyrgyzstan, as measured by the number of antenatal checkups, was higher than in Tajikistan. The most frequently mentioned preparatory arrangement for the birth was to save money. Table 2 shows that in Kyrgyzstan a vast majority of women (84\%) planned to give birth in the nearest maternity clinic, while in Tajikistan more than one in five (21\%) planned to give birth at 
Wiegers, T.A., Boerma, W.G.W., Haan, O. de. Maternity care and birth preparedness in rural Kyrgyzstan and Tajikistan. Sexual \& Reproductive Healthcare: 2010, 1(4), 189-194

home. A traditional birth assistant (TBA) is mentioned by 15\% of women in Tajikistan as the person expected to be present at the birth.

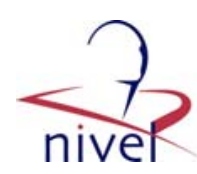

\section{Knowledge and communication skills of providers}

Physicians in Kyrgyzstan scored an average of 55\% correct answers on the 52 knowledge questions about antenatal care, normal labour and childbirth, newborn care, management of complications, postnatal care, and postnatal haemorrhage (see Table 3). All other providers: midwives and nurses in Kyrgyzstan, physicians and midwives in Tajikistan, scored on average less than 50 percent correct answers. In Tajikistan seven out of 30 providers (23\%) observed during a consultation received the label 'competent', based on the communication and counselling skills checklist and the opinion of the trained observer. In Kyrgyzstan 18 providers were observed, of whom none received the label 'competent'.

[TABLE 1, 2, 3]

\section{Facility audit}

In seven out of 15 facilities in rural Kyrgyzstan (47\%) staff was permanently available for treatment and referral of patients ( $24 \mathrm{~h}$ a day, 7 days a week). In Tajikistan this was the case in only two out of 17 facilities (12\%). Examination rooms with adequate privacy were almost generally available, that is: in all Kyrgyz facilities and in all but one Tajik facilities. Most facilities had at least some of the basic equipment and supplies at their disposal, as measured with a list of 50 items. The available number of items of equipment and supplies was higher in Kyrgyzstan, on average 30, than in Tajikistan, with an average of 19. Additional infrastructure, staff, equipment and supplies, for instance: staff and equipment to perform blood transfusions or caesarean sections, were scarce in both countries.

\section{DISCUSSION}

This study has shown that rural Kyrgyz and Tajik women and men have limited knowledge about possible complications during pregnancy, childbirth, and the period after childbirth. Tajik women seem to be better informed than Kyrgyz women, but Kyrgyz women seem to make more use of available healthcare facilities. Most women in both countries reported to see a midwife or physician for antenatal check ups. The frequency of visits was much higher in Kyrgyzstan than in Tajikistan. A study by Habibov and Fan showed that prenatal care utilization in Tajikistan decreased dramatically since the collapse of the Soviet Union [6]. Kyrgyz women much more frequently visited family doctors for antenatal care than women in Tajikistan. This may be related to the family medicine reform, which is much stronger in Kyrgyzstan than in other Central Asian countries [17]. Home birth is almost unknown in Kyrgyzstan and was also unusual in Tajikistan before independence in 1991. Falkingham has shown conclusively that the use of maternal health care services in Tajikistan, including medical facilities for childbirth, has fallen significantly since independence, especially in rural areas, resulting in an increasing home birth rate and, more worrisome, a dramatic increase in the proportion of women giving birth at home without skilled assistance [11]. In this study we found that in Tajikistan 15\% of women planned to have a traditional birth assistant, rather than a regular health professional (nurse, midwife, family practitioner or gynaecologist), to assist with the birth, compared to none in Kyrgyzstan. Knowledge tests among care providers in rural areas of Kyrgyzstan and Tajikistan had very poor results. In both countries none of the tested providers passed the criteria on all themes of the test, meaning that none of the providers met the Safe Motherhood standard for a professional level of medical technical knowledge on pregnancy, delivery and the postpartum period, including infant care. This points to a poor quality of care, and in fact to a dangerous environment for mother and child. In addition, only a few of the providers received the label 'competent' in basic communication and counselling skills. Service providers, being obstetricians/ gynaecologists, family doctors, midwives and nurses, apparently do not see trustful interaction with their patients as belonging to their professional competencies. This can be interpreted as a medical technical attitude of the providers towards perinatal issues with little or no attention to providing information and preventive medicine [1]. Results of the facilities audit showed that in half of the audited facilities in Kyrgyzstan and only in $12 \%$ of those in 
Wiegers, T.A., Boerma, W.G.W., Haan, O. de. Maternity care and birth preparedness in rural Kyrgyzstan and Tajikistan. Sexual \& Reproductive Healthcare: 2010, 1(4), 189-194

Tajikistan medical staff were permanently available for treatment and referral of pregnant women. Overał, the presence of basic equipment was insufficient, although somewhat better in Kyrgyzstan than in Tajikistan. Additional equipment, supplies and staff were scarce in both countries.

\section{CONCLUSION}

The conclusion about the level of knowledge of the rural populations of Kyrgyzstan and Tajikistan about pregnancy and childbirth is that on average they know little about danger signs or about possible complications during pregnancy and the postpartum period. The conclusion about the service providers is that they do not have an adequate professional level of knowledge on perinatal health issues and lack basic skills to monitor their work. In other words, although they are regular health professionals they are not the skilled birth attendants as meant by the Safe Motherhood terminology. However, is should be kept in mind that doctors and midwives mostly work in poorly equipped environments, where basic instruments and hygiene are lacking and referral services in case of complications are absent, as often no transport to the nearest hospital is available. Population-directed recommendations for the project 'Services to the people' are:

(a) to provide Birth Preparedness Courses for women and important others around them. This may directly result in earlier recognition of danger signs and earlier detection of complications;

(b) to provide information on physiological processes during pregnancy and delivery. This will reduce the fear for the unknown and may therefore lead to a reduction of complications;

(c) to teach pregnant women techniques to deal with contractions and provide them with information about breastfeeding and nutrition. This will result in more healthy birth outcomes.

Since completion of this baseline study Birth Preparation Courses ('Parent Schools') for pregnant women and their partners or trusted companions and educational courses for maternity care providers have been introduced in both countries and in Kyrgyzstan a Safe Motherhood Community Fund has been established. This project is one of a series of projects to help improve healthcare and public health in former Soviet countries, funded by national and international organisations as the European Union and the World Health Organisation [18-20].

\section{Strengths and weaknesses of the study}

This study has provided the project 'Services to the people' with valuable information about the level of knowledge in rural districts of Kyrgyzstan and Tajikistan. Based on these results they have been able to tailor their Birth Preparation Courses to the needs of the people and their training program for professionals to the level of knowledge and skills of the maternity care providers. The main weakness of the study is in the possible conflict of interest within the local family planning organisations. Researchers from abroad were involved in the design and preparation of the study and the data analysis, the Ministry of Health in both countries approved and supported the study but the data collection, including the training of research assistants, was a local activity, coordinated by the family planning associations in Kyrgyzstan and Tajikistan. However, the interviewers and observers were employed by the respective National Associations and they were not involved in the local service provision.

\section{Statement of funding}

The project is funded by the Dutch Ministry of Foreign Affairs.

\section{Conflict of interest}

None declared. 


\section{ACKNOWLEDGEMENTS}

The authors thank Tatiana Popovitskaya from the Reproductive Health Alliance Kyrgyzstan and Shamsidin Kurbonov and Ravshan Tohirov from the Tajic Family Planning Alliance for their cooperation in making this project possible. And special thanks to Eliza Maldibaeva, Husein Aminov and Zebo Usupova for collecting the data.

\section{REFERENCES}

[1] Wiegers TA, Boerma WGW, de Haan O, Askerov A, Popovitskaya T, Kurbonov S, et al. Safe motherhood. Preparedness for birth in rural Kyrgyzstan and Tajikistan. Knowledge and perception of women, men and health professionals and the quality of maternity care facilities. Amsterdam: NSPOH; 2006.

[2] Tedioso F, Aye R, Ibodova S, Thompson R, Wyss K. Access to medicines and out of pocket payments for primary care: evidence from family medicine users in rural Tajikistan. BMC Health Serv Res 2008(8):109.

[3] OECD Health Data, 2010. Available from: http://www.oecd.org.

[4] WHO Country Information: Tajikistan, Kyrgyzstan. Basis statistics from the health for all (HFA) database, 2005. Available from: http://www.euro.who.int/ hfadb.

[5] Balabanova D, McKee M, Pomerleau J, Rose R, Haerpfer C. Health service utilization in the former soviet union: evidence from eight countries. Health Serv Res 2004;39(6):1927-50.

[6] Habibov NN, Fan L. Modelling prenatal health care utilization in Tajikistan using a two-stage approach: implications for policy and research. Health Policy Plan 2008;28:443-51.

[7] Kutzin J, Ibraimova A, Jacab M, O'Dougherty S. Bismarck meets Beveridge on the Silk Road: coordinating funding sources to create a universal health financing system in Kyrgyzstan. Bull World Health Org 2009;87:549-54.

[8] Veenema TG. Health systems and maternal and child survival in Centra Asian Republics. J Nurs Scholarsh 2000;32(3):301-6.

[9] European Observatory on Health Care Systems. Health care systems in transition: Tajikistan. WHO/European Observatory on Health Care Systems, editor. Copenhagen; 2000.

[10] European Observatory on Health Care Systems. Health care systems in transition: Kyrgyzstan. WHO/European Observatory on Health Care Systems, editor. Copenhagen; 2005.

[11] Falkingham J. Inequality and changes in women's use of maternal healthcare services in Tajikistan. Stud Family Plan 2003;34(1):32-43.

[12] WHO Global Health Atlas. Available from: http://apps.who.int/globalatlas/ DataQuery/default.asp [accessed 26.07.10].

[13] WHO, UNICEF, UNFPA. Maternal mortality in 2000: estimates developed by WHO, UNICEF and UNFPA. Geneva: World Health Organization; 2000.

[14] European Observatory on Health Care Systems. Health care systems in transition: Kyrgyzstan. WHO/European Observatory on Health Care Systems, editor. Copenhagen; 2000.

[15] Johns Hopkins University, JHPIEGO 2004, 2007. Available from: http:// www.jhpiego.org/resources/pubs/mnh/bpcrmatrix.pdf.

[16] Johns Hopkins University, JHPIEGO 2004, 2008. http://www.jhpiego.org/ resources/pubs/mnh/BPCRtoolkit.pdf.

[17] Hardison C, Fonken P, Chew T, Smith B. The emergence of family medicine in Kyrgyzstan. Family Med 2007;39(9):627-33.

[18] Mashta O. Building capacity for primary care in Tajikistan. Lancet 2000;355(9200):295.

[19] O'Brien V, Djusipov K, Kudaibergonova T. Public health challenges in Kyrgyzstan: developing a new curriculum. Rural Remote Health 2005;5(4):461.

[20] Parfitt BA, Cornish F. Implementing family health nursing in Tajikistan: from policy to practice in primary health care reform. Soc Sci Med 2007;65(8):1720-9. 
[вох 1]

Box 1

Danger signs.

The key danger signs during pregnancy include:

- Severe vaginal bleeding, swollen hands/face, blurred vision.

The key danger signs during labour and childbirth include:

- Severe vaginal bleeding, prolonged labour (>12 h), convulsions, retained placenta.

The key danger signs during the postpartum period include:

- Severe vaginal bleeding, foul-smelling vaginal discharge, high fever.

The key danger signs in the newborn include:

- Convulsions/spasms/rigidity, difficult/fast breathing, very small baby, lethargy/unconsciousness.

These 14 danger signs were selected as key by the Safe Motherhood Initiative because they are common, easy to recognize, and associated with a potentially severe problem. 
Box 2

Example question from the providers' questionnaire.

One example of a question concerning antenatal care is:

8. Focused antenatal care includes which of the following actions?

a. __ Checking the baby's position at 28 weeks

b. __ Checking the woman's blood pressure at every visit

c. ___ Assessing ankle oedema at 36 weeks

d. ___ Counselling the woman about risk signs only at the last visit

(The correct answer is b. according to the answer key, included in the Toolkit)

N.B.: Focused antenatal care means that providers focus on assessment and actions needed to make decisions, and provide care for each woman's individual situation.

See: http://www.whiteribbonalliance.org/Resources/Documents/Focused\%20Antenatal\%20Care_Best\%20Practices_JHIPEGO.pdf for more information about focused antenatal care. 


\section{[TABLE 1]}

\section{Table 1}

Birth preparedness.

\begin{tabular}{|c|c|c|c|c|}
\hline & \multicolumn{2}{|c|}{ Kyrgyzstan } & \multicolumn{2}{|c|}{ Tajikistan } \\
\hline & $\begin{array}{l}\text { Women } \\
n=118\end{array}$ & $\begin{array}{l}\text { Men } \\
n=31\end{array}$ & $\begin{array}{l}\text { Women } \\
n=100\end{array}$ & $\begin{array}{l}\text { Men } \\
n=20\end{array}$ \\
\hline Check-ups during pregnancy by: & $\%$ & $\%$ & $\%$ & $\%$ \\
\hline Midwife/gynaecologist & 65 & 52 & 73 & 20 \\
\hline Nurse/midwife & 19 & 10 & 63 & 20 \\
\hline Clinical officer health facility & 3 & 7 & 4 & 20 \\
\hline TBA (traditional birth assistant) & 1 & - & 8 & 30 \\
\hline Family practitioner & 25 & 42 & 2 & 5 \\
\hline Relative/friend/other person & 8 & 7 & 13 & - \\
\hline Nobody & - & 3 & - & - \\
\hline Number of planned antenatal visits: & & n.a. & & n.a. \\
\hline Average (median) & \multicolumn{2}{|l|}{$9.7(9.0)$} & \multicolumn{2}{|c|}{$5.2(5.0)$} \\
\hline Arrangements for the birth: & $\%$ & $\%$ & $\%$ & $\%$ \\
\hline Identify transport & 20 & 16 & 8 & 20 \\
\hline Save money & 42 & 55 & 57 & 80 \\
\hline Identify skilled provider & 12 & 10 & 2 & 10 \\
\hline Prepare necessary medicines & 15 & 39 & 16 & 30 \\
\hline Other & 54 & 36 & 32 & - \\
\hline Way of preparation: & $\%$ & $\%$ & $\%$ & $\%$ \\
\hline Read about birth & 17 & 26 & 2 & - \\
\hline Watch instructive films/videos & 1 & - & - & 5 \\
\hline Ask questions to midwife/provider & 27 & 23 & 37 & 5 \\
\hline Talk with other women & 19 & - & 14 & 5 \\
\hline Talk with mother-in-law & 14 & - & 24 & 5 \\
\hline Talk with female relatives & 20 & 7 & 24 & - \\
\hline A course for future parents & 7 & 7 & - & - \\
\hline No specific preparation & 17 & 29 & 5 & 50 \\
\hline
\end{tabular}

n.a. $=$ not asked. 


\section{[TABLE 2]}

\section{Table 2}

(Planned) place of birth and birth assistance, (planned) action. ${ }^{a}$

\begin{tabular}{|c|c|c|c|c|}
\hline & \multicolumn{2}{|c|}{ Kyrgyzstan } & \multicolumn{2}{|c|}{ Tajikistan } \\
\hline & $\begin{array}{l}\text { Women } \\
n=118\end{array}$ & $\begin{array}{l}\text { Men } \\
n=31\end{array}$ & $\begin{array}{l}\text { Women } \\
n=100\end{array}$ & $\begin{array}{l}\text { Men } \\
n=20\end{array}$ \\
\hline (Planned) place of birth: & $\%$ & $\%$ & $\%$ & $\%$ \\
\hline Own home/TBA's home & 1 & 10 & 23 & 35 \\
\hline Government hospital & 2 & 10 & 29 & 15 \\
\hline Government local facility & 84 & 71 & 48 & 45 \\
\hline Private or maternity hospital/other & 9 & 7 & - & - \\
\hline Planned birth assistant: & $\%$ & n.a. & $\%$ & n.a. \\
\hline Doctor & 61 & & 60 & \\
\hline Nurse/midwife & 43 & & 66 & \\
\hline TBA & - & & 15 & \\
\hline Other/do not know & 8 & & 8 & \\
\hline $\begin{array}{l}\text { (Planned) action at first signs of the } \\
\text { coming birth: }\end{array}$ & $\%$ & $\%$ & $\%$ & $\%$ \\
\hline Start timing contractions & 16 & - & 4 & - \\
\hline Let my doctor know & 9 & 3 & 5 & 10 \\
\hline Let my husband know & 42 & & 33 & \\
\hline Start packing things & 25 & 16 & 8 & - \\
\hline Take prepared bag with things & 32 & 13 & 46 & - \\
\hline Call ambulance or other transport & 35 & 58 & 12 & 15 \\
\hline Call doctor/midwife/TBA to come & 2 & 13 & 19 & - \\
\hline Start preparing place for the birth & - & 3 & 2 & - \\
\hline Check if place has been prepared & - & - & 2 & 5 \\
\hline Other & 17 & 23 & 20 & - \\
\hline Do not know & 1 & 3 & 5 & 65 \\
\hline
\end{tabular}

n.a. $=$ not asked.

a 'Planned' for women in their present pregnancy, 'actual' for men in relation to pregnancies of their wife. 
Wiegers, T.A., Boerma, W.G.W., Haan, O. de. Maternity care and birth preparedness in rural Kyrgyzstan and Tajikistan. Sexual \& Reproductive Healthcare: 2010, 1(4), 189-194

\section{[TABLE 3]}

\section{Table 3}

Provider knowledge.

\begin{tabular}{|c|c|c|c|c|}
\hline \multirow[t]{2}{*}{ Provider } & \multicolumn{2}{|l|}{ Kyrgyzstan } & \multicolumn{2}{|l|}{ Tajikistan } \\
\hline & $\begin{array}{l}\text { Gynaecologists, } \\
\text { family doctors } \\
n=19\end{array}$ & $\begin{array}{l}\text { Midwives, } \\
\text { nurses } \\
n=8\end{array}$ & $\begin{array}{l}\text { Obstetrician/ } \\
\text { gynaecologists } \\
n=28\end{array}$ & $\begin{array}{l}\text { Midwives } \\
n=2\end{array}$ \\
\hline $\begin{array}{l}\text { Themes (no. of } \\
\text { questions) }\end{array}$ & $\%$ correct & $\%$ correct & $\%$ correct & $\%$ correct \\
\hline Antenatal care (9) & 57 & 58 & 45 & 56 \\
\hline $\begin{array}{l}\text { Normal labour } \\
\text { and childbirth } \\
\text { (9) }\end{array}$ & 40 & 33 & 26 & 17 \\
\hline $\begin{array}{l}\text { Newborn care } \\
\text { (10) }\end{array}$ & 49 & 44 & 49 & 40 \\
\hline $\begin{array}{l}\text { Management of } \\
\text { complications } \\
\text { (8) }\end{array}$ & 58 & 48 & 55 & 44 \\
\hline $\begin{array}{l}\text { Postnatal care } \\
\text { (10) }\end{array}$ & 70 & 58 & 60 & 55 \\
\hline $\begin{array}{l}\text { Postnatal } \\
\text { haemorrhage } \\
\text { (6) }\end{array}$ & 56 & 48 & 52 & 42 \\
\hline Total results (52) & 55 & 48 & 47 & 42 \\
\hline
\end{tabular}

